\author{
(C) В.А. Соколов, С.А. Мамаева, Я.Л. Бутрин, А.А. Герасимова
}

Военно-медицинская академия имени С.М. Кирова МО РФ, Санкт-Петербург, Россия

Резюме. Представлены данные об опыте создания в Советском Союзе первых специализированных отделений для лечения пострадавших от термической травмы. Активную позицию в этом процессе заняли выдающиеся представители военной медицины: И.И. Джанелидзе, С.С. Гирголав, И.С. Колесников, Б.Н. Постников, Т.Я. Арьев и др. Тематика научных исследований и публикаций данных авторов, а также их коллег из различных научно-исследовательских и лечебных учреждений нашей страны свидетельствует о том, что ожоги и отморожения являлись для ученых того времени весьма актуальной научной проблемой. Однако в силу объективных причин исследования проводились разрозненно, зачастую были направлены на решение частных задач, не имели подтверждения в клинических условиях. Ситуация коренным образом изменилась после создания в 1960 г. в Военно-медицинской академии им. С.М. Кирова кафедры термических поражений с клиникой на 100 коек. Первым ее начальником стал Т.Я. Арьев. Высококвалифицированный ученый, всесторонне подготовленный хирург, педагог с большим стажем работы, опытный методист смог в короткое время сформировать коллектив единомышленников. Под его руководством и при его непосредственном участии кафедра приступила к решению широкого перечня актуальных научных проблем, связанных с термической травмой. Об этом свидетельствует перечень тем и названий публикаций, которые были найдены в фундаментальной библиотеке Военно-медицинской академии им. С.М. Кирова. Бережное отношение к публикациям того времени имеет большое воспитательное значение для курсантов, слушателей, студентов и всех сотрудников академии. Таким образом мы сохраняем память о тех представителях военной медицины, которые создавали историю и славу нашей академии.

Ключевые слова: военная медицина; Т.Я. Арьев; Военно-медицинская академия; ожоговые отделения; научные исследования ожоговой травмы; термические поражения; военно-полевая хирургия; кафедра термических поражений; ожоговая болезнь; местное лечение и хирургия ожогов.

Как цитировать:

Соколов В.А., Мамаева С.А., Бутрин Я.Л., Герасимова А.А. Вклад профессора Тувия Яковлевича Арьева в разработку актуальных вопросов термической травмы. Тематика основных исследований и публикаций за 1958-1972 г. // Вестник Российской военно-медицинской академии. 2021. Т. 23, № 2. C. 253-260. DOl: https://doi.org/10.17816/brmma.71313 
DOl: https://doi.org/10.17816/brmma.71313

\title{
CONTRIBUTION OF PROFESSOR TUVIY YAKOVLEVICH ARYEV TO DEVELOPMENT OF TOPICAL ISSUES OF THERMAL TRAUMA. MAIN RESEARCH AND PUBLICATIONS FOR 1958-1972
}

\author{
(C) V.A. Sokolov, S.A. Mamaeva, Ya.L. Butrin, A.A. Gerasimova \\ Military Medical Academy named after S.M. Kirov of the Ministry of Defense of the Russian Federation,, Saint Petersburg, Russia
}

ABSTRACT: The data on the experience of creating the first specialized departments for the treatment of victims of thermal injury in the Soviet Union are presented. Outstanding representatives of military medicine took an active position in this process: I.I. Dzhanelidze, S.S. Girgolav, I.S. Kolesnikov, B.N. Postnikov, T.Ya. Ariev, etc. The topic of their scientific research and publications, as well as of colleagues from various research and medical institutions in our country, indicates that burns and frostbite were a very urgent scientific problem for scientists of that time. However, due to objective reasons, the studies were carried out separately, were often aimed at solving particular problems, and had no confirmation in a clinical setting. The situation changed radically after the creation in 1960 at the Military Medical Academy named after S.M. Kirov Department of Thermal Injuries with a clinic for 100 beds. Its first boss was T.Ya. Ariev. A highly qualified scientist, a comprehensively trained surgeon, a teacher with extensive work experience, an experienced methodologist was able to form a team of likeminded people in a short time. Under his leadership and with his direct participation, the department began to solve a wide range of urgent scientific problems associated with thermal injury. This is evidenced by the list of topics and titles of publications that were found in the fundamental library of the Military Medical Academy named after S.M. Kirov. A careful attitude to the publications of that time is of great educational value for the student cadets, trainees, students and all employees of the academy. Thus, we preserve the memory of those representatives of military medicine who created the history and glory of our academy.

Keywords: military medicine; T.Ya. Ariev; Military Medical Academy; burn departments; scientific research of burn injury; thermal injuries; military field surgery; department of thermal injuries; burn disease; local treatment and surgery of burns.

To cite this article:

Sokolov VA, Mamaeva SA, Butrin YaL, Gerasimova AA. Contribution of professor Tuviy Yakovlevich Aryev to development of topical issues of thermal trauma. Main research and publications for 1958-1972. Bulletin of the Russian Military Medical Academy. 2021;23(2): 253-260. DOI: https://doi.org/10.17816/brmma.71313 
Выступая 15 октября 1957 г. на заседании Московского хирургического общества, посвященном 40-летию Великой Октябрьской социалистической революции, выдающийся советский хирург, в годы войны первый заместитель главного хирурга Красной армии В.С. Левит констатировал: «...кончилась Великая Отечественная война. Перед хирургами поставлены актуальные задачи мирной хирургии. Многочисленные школы советских хирургов стали разрабатывать новые проблемы, стремясь полнее удовлетворить все возрастающие запросы нашей страны в области здравоохранения». Среди двенадцати «...главных задач, которые должны быть решены в недалеком будущем...» перед профессиональным сообществом хирургов автор назвал: «...дальнейшее углубление изучения вопросов травматизма, изучение патогенеза ожоговой болезни и лечения ожогов, дальнейшее улучшение методов преподавания хирургии» - вторая, третья и двенадцатая в списке задач соответственно.

Проблема ожогов возникла не случайно. Страна возвращалась к мирной жизни. Шло восстановление производственных мощностей, жилищного фонда, коммунального хозяйства, активизировались работы в колхозах и совхозах. К сожалению, данный процесс сопровождался производственным и бытовым травматизмом, в структуре которого были и ожоги различной этиологии. А единых взглядов на патогенез, концепцию общего, местного и хирургического лечения данной группы пострадавших у отечественных хирургов да и у их зарубежных коллег в то время не было [1]. Не лучше обстояло дело с организацией и работой первых специализированных отделений. Так, в 1946 г. по инициативе академика Академии медицинских наук (АМН) Союза Советских Социалистических Республик (СССР) И.И. Джанелидзе в Ленинграде, в Научно-исследовательском институте скорой помощи (НИИСП), было создано первое ожоговое отделение не только в городе, но и в стране. За пять лет работы (1946-1950) в нем пролечилось свыше 2000 больных, преимущественно (93,2\%) со свежими термическими поражениями [2]. Однако после смерти И.И. Джанелидзе в 1950 г. НИИСП закрывают. В Москве в 1947 г. директор Института экспериментальной и клинической хирургии АМН СССР академик А.В. Вишневский поручил профессору Г.В. Вилявину развернуть койки, предназначенные для лечения ожоговых больных. Но лишь в 1960 г. выделенные палаты и койки получили статус «ожогового отделения».

Тем не менее был получен практический опыт лечения пострадавших от ожогов различной этиологии. Отрабатывалось взаимодействие совместной работы хирургов со специалистами других профилей. Это создало предпосылки для фундаментального изучения проблемы ожогов и совершенствования методов их лечения [3].

Кроме гражданского здравоохранения рассматриваемая патология являлась актуальной и для военных медиков. Помимо вышеперечисленных задач, их внимание привлекала военно-медицинская составляющая проблемы. Во многом это было связано с принятием на вооружение ядерного оружия и боевых зажигательных смесей. Поражающее действие светового излучения ядерного взрыва, пламени, высокой температуры, вдыхание токсических продуктов горения, в случае применения напалма, и т. д. коренным образом меняло структуру санитарных потерь. Требовались решения, направленные на адаптацию доктрины медицинского обеспечения войск к реалиям войны того времени. Необходимо было ее детально изучить и выработать конкретные практические рекомендации. Ситуация осложнялась не только новизной, но и противоречивыми результатами исследований, опубликованных за рубежом. Подтверждением этому служит публикация сотрудников Военно-медицинской академии им. С.М. Кирова (ВМА) профессора И.С. Колесникова и доктора медицинских наук В.Н. Шейниса «Основные положения лечения ожогов за рубежом» [4]. На основании личного опыта и анализа иностранной научной литературы авторы пришли к выводу: «...количество сообщений на тему лечения ...термических ожогов... велико, особенно в последнее время, когда военные действия в Корее и "атомный ажиотаж" на Западе усугубили интерес к проблеме ожогов. Однако многие из этих публикаций повторяют одинаковые воззрения или посвящены несуществующим, или недостоверным деталям вопроса». Анализ представленных результатов исследований «...затрудняется значительными различиями во взглядах на существо патологии ожогов и противоречивостью мнений о целесообразности и эффективности... многочисленных средств и методов, предлагаемых для лечения ожогов».

Ученые ВМА не только констатировали сложность данной проблемы, они активно работали над ее разрешением. Например, на кафедре военно-полевой хирургии В.А. Долинин в докторском диссертационном исследовании изучал особенности напалмовых ожогов и их лечения на этапах медицинской эвакуации [5]. Частные вопросы данной проблемы изучались в те годы и на других кафедрах ВМА: глазных болезней, хирургии усовершенствования врачей № 2 [6].

В 1951 г. по инициативе начальника кафедры госпитальной хирургии академика АМН СССР генераллейтенанта медицинской службы С.С. Гирголава и его будущего преемника И.С. Колесникова на кафедре развертывается ожоговое отделение на 25 коек. С сентября 1958 г. его коечная емкость увеличивается до 50 коек [7]. С 1951 по 1960 г. в нем лечилось более 2500 больных не только из Ленинграда, но и других лечебных учреждений Советского Союза [7]. Накопленный опыт организации и материально-технического обеспечения лечебного процесса тщательно систематизировался и анализировался. И в 1960 г. был опубликован И.С. Колесниковым и др. в журнале «Вестник хирургии им. Грекова» в разделе «В помощь практикующему врачу» 
в статье «К обеспечению работы специализированного ожогового отделения для лечения обожженных» [7].

Активную работу по изучению разнообразных аспектов лечения ожогов различной этиологии проводили и сотрудники кафедры, которых направляли для прохождения службы в другие города. Так, в 1951 г. ученик С.С. Гирголава профессор Т.Я. Арьев вместе группой лиц профессорско-преподавательского состава ВМА направляется в Саратов, где вновь начинает формироваться Военно-медицинский факультет при местном медицинском институте. Возглавив кафедру Военно-полевой хирургии, Т.Я. Арьев менее чем за год на базе 1-й городской клинической больницы им. В.И. Ленина развернул ожоговое отделение на 25 коек. В нем за 5 лет, с 1952 по 1957 г., находилось на лечении 542 обожженных в возрасте от 1 года до 88 лет [1].

После принятия решения о расформировании факультета Т.Я. Арьев возвращается в Ленинград в ВМА на кафедру госпитальной хирургии № 1. Решением ученого совета академии от 26.10.1959 он избирается заместителем начальника этой кафедры. Являясь высококвалифицированным научным работником, имея достаточно серьезный опыт руководства клинической кафедрой, а также лечения ожогов различной этиологии в условиях специализированного отделения, он активно включился в многоплановую текущую работу. В частности, стал одним из организаторов и редакторов научной конференции по проблеме «Ожоги» и сборника тезисов докладов. В форуме, который прошел в Ленинграде с 6 по 8 мая 1959 г. [6], приняли участие сотрудники многих кафедр академии: военно-полевой хирургии, глазных болезней, госпитальной хирургии № 1, кожных и венерических болезней, рентгенологии, факультетской терапии № 1, фармакологии, хирургии усовершенствования врачей № 2, челюстно-лицевой хирургии, ряда научно-исследовательских лабораторий и др. Вместе с ними итоги своих исследований представили коллеги из научно-исследовательских и медицинских учреждений, расположенных в различных регионах Советского Союза: Астрахани, Белоруссии, Воронежа, Иваново, Каунаса, Ленинградского педиатрического института, Львова, Москвы, Новосибирска, Одессы, Риги, Рязанского медицинского института, Саратова, Северо-Кавказского и Сибирского военных округов, Сталинграда, Читы. Поражает количество докладов и разнообразие их тематики: хирургия ожогов - 17, внутренняя патология при ожоговой болезни - 12, лечение термических ожогов - 10, комбинированные терморадиационные поражения - 10, местное лечение ожогов - 4, ожоги глаз - 3, напалмовые ожоги - 3, изучение ожогов в эксперименте - 3, вопросы обезболивания и анестезии - 2. Проблеме ожогового шока, применению физических лечебных факторов, этапному лечению обожженных, методике определения площади ожога, лечебному питанию было посвящено по одной работе.
Опубликованные в сборнике тезисы научных докладов свидетельствуют о том, что в конце 1950-х гг. проблема изучения различных аспектов ожоговой травмы являлась одним из актуальных разделов отечественной медицинской науки.

Как констатировали Б.С. Вихриев и В.М. Бурмистров (1986), за 15 послевоенных лет в нашей стране «...в изучении различных сторон патогенеза и лечения ожогов приняли участие не только хирурги, но и представители других клинических и теоретических специальностей (терапевты, психиатры, невропатологи, патоморфологи т. д.). Углубились и расширились представления о совокупности нарушений жизнедеятельности организма пострадавшего, объединяемых понятием «ожоговая болезнь», была создана патогенетически обоснованная система ее лечения. В итоге необходимость в специализированных лечебных учреждениях для пострадавших от ожогов, теоретически представлявшаяся очевидной и раньше, была доказана на практике».

Ситуация кардинально изменилась, когда директивой заместителя министра обороны - начальника тыла Вооруженных сил СССР Маршала Советского Союза И.Х. Баграмяна № ШТ 27.112.47 от 4.06.1960 в штат ВМА была включена кафедра термических поражений с клиникой на 100 коек (мужское и женско-детское отделения). В ее состав вошла и научно-исследовательская лаборатория ожоговой травмы.

Не имеющая аналогов в мире кафедра термических поражений стала научным, лечебным и учебным учреждением, объединившим различных специалистов: хирургов, терапевтов, бактериологов, патологоанатомов, патофизиологов, биохимиков - в деле изучения ожогов, их лечения, а также преподавания термической патологии слушателям академии, студентам и врачам различных профилей подготовки [3].

Первым начальником кафедры термических поражений стал Т.Я. Арьев. Ему вместе с коллективом кафедры предстояло приступить к комплексному решению множества научных проблем, связанных с теорией и практикой местного и общего лечения ожогов.

Термин «ожоговая болезнь» первым применил в 1938 г. W.C. Wilson [8]. Однако широкое его распространение, по мнению Л.М. Клячкина [3], произошло лишь к концу 1950-х годов: «...в результате накопленных знаний в области термической патологии был сформулирован взгляд, что ожоги вызывают своеобразный процесс, касающийся всех органов и систем, - ожоговую болезнь. Закономерность и специфичность патологических реакций целостного организма на ожоговую травму его покровов дают... основание считать ожоговую болезнь самостоятельной нозологической формой. <...> Изменения органов, вторичные по своему существу, часто приобретают самостоятельное значение, определяя течение и исход ожоговой болезни». А выпадение функций кожи вследствие ее разрушения при глубоком 
ожоге рассматривалось как основной патогенетический фактор ожоговой болезни.

При этом подавляющее большинство исследований того времени, посвященных термическим ожогам и выполненных патологами или экспериментаторами, В своей основе имело лишь частные аспекты изучения ожоговой травмы. Они, безусловно, внесли важный вклад в дело создания целостного представления о динамике висцеральных сдвигов в организме обожженного, но, естественно, не охватывали проблемы полностью [3]. Поэтому тематика первых фундаментальных исследований была посвящена изучению влияния некомпенсируемой утраты кожного покрова как физиологической системы, раневого воспаления на участках ожога на запуск механизмов развития ожоговой болезни. Результаты проведенных работ изложены Т.Я. Арьевым в тезисах научного доклада «0 влиянии утраты кожного покрова на летальность, принципы лечения и патогенез ожоговой болезни» (1962) и статье «0 влиянии утрат кожного покрова на летальность, патогенез и принципы лечения ожоговой болезни» [9].

Актуальные вопросы классификации, клиники, лечения и осложнений ожоговой болезни изложены в следующих публикациях: «0 некоторых спорных вопросах современного лечения ожогов [10], «0 влиянии утрат кожного покрова на летальность, принципы лечения и патогенез ожоговой болезни» [11], «Ожоговая болезнь (клиника, патогенез, принципы лечения)» [12], «Достоверное, вероятное и сомнительное в современных представлениях об ожоговой болезни» [13], «Современные представления об ожоговом шоке» [14] и ряде других работ.

Кафедральный опыт и тактика местного лечения ожогов приведены в ряде работ и докладе на заседании хирургического общества им. Н.И. Пирогова 5 февраля 1964 г.: «Местное лечение ожогов» [15], «Ожоговые раны: доклад» (1964).

Однако в сравнении с вышеизложенной тематикой изучение разнообразных аспектов хирургии ожогов, в том числе возможностей кожной пластики при лечении ран различной этиологии, стало одним из приоритетных направлений в научных исследованиях как начальника, так и сотрудников кафедры: «Хирургия ожогов: критический обзор современной зарубежной литературы» [16], «Хирургия ожогов» [17], «Некоторые итоги и перспективы развития современной хирургии ожогов» [18], «Современная кожная пластика» [19] и др.

С учетом новизны решаемых на кафедре задач в профессиональном сообществе периодически возникали проблемные и спорные вопросы. В таких ситуациях Т.Я. Арьев излагал авторскую точку и позицию кафедры в следующих публикациях: «0 некоторых спорных вопросах современного лечения ожогов» [20], «Проблема ожогов в СССР» [21], «06 особенностях ожогов как травмы человека» [22] и др.
Кроме того, Т.Я. Арьев рецензировал труды сотрудников других клиник. Например, им подготовлены рецензии на книгу П.И. Шилова и П.И. Пилюшина «Внутренняя патология при ожогах. Л.: Медгиз, 1962» (1963) и статьи: «0 так называемой комплексной терапии травматического шока. По поводу статьи А. Н. Беркутова «О лечении травматического шока» в «Военно-медицинском журнале» (1964), а также «Классификация отморожений: по поводу статьи Г.А. Бежаева «К вопросу о классификации отморожений» в журнале «Клиническая хирургия», 1966, № 4» (1966). Т.Я. Арьев продолжал работу и руководство исследованиями по влиянию низких температур на ткани и организм человека. Результаты проведенных работ также были опубликованы в 1962-1969 гг.

За время руководства кафедрой термических поражений Т.Я. Арьев активно участвовал в научных конференциях по проблемам "Ожоги» и "Отморожения», проводимых в Советском Союзе. Кроме того, в период с 1961 по 1965 гг. он достойно представлял нашу страну на международных конгрессах и симпозиумах по пластической хирургии и термическим поражениям, проводимых в Великобритании, Италии, Чехословакии. Анализ представленных на них материалов он обобщил в ряде аналитических работ и выступлении в научном обществе: «Симпозиум чехословацкой пластической хирургии 28-30/VI 1960 г. в г. Марианске-Лазне» (1961), «ll Всемирный конгресс по проблеме ожогов: [Эдинбург (Шотландия), сент. 1965 г.]» [23], «Впечатления о II Всемирном конгрессе по проблеме ожогов и об английских ожоговых центрах: доклад» (1966).

Большое значение Т.Я. Арьев придавал разработке вопросов оказания помощи обожженным на этапах медицинской эвакуации, внедрению современных методов диагностики, лечения и профилактики термической травмы в войсковом звене. Этим вопросам он посвятил несколько публикаций в сборнике трудов ВМА, «Военно-медицинском журнале» и научно-популярном журнале «Военные знания»: «Организационные и клинические принципы оказания медицинской помощи и лечения обожженных в условиях современной войны» [24], «0 транспортировке тяжелообоженных на большие расстояния» [25] и др.

Накопленный значительный клинический опыт лечения разнообразной патологии коллективом клиники, результаты скрупулезного анализа отечественной и зарубежной литературы, осведомленность в достижениях советских и иностранных специалистов, а также проблемных вопросах, стоящих перед различными научными коллективами, и перспективные пути их решения обобщены в следующих монографиях: «Частная хирургия: руководство для врачей» [26], «Отморожение» [27]. А наиболее значимым событием в современной отечественной комбустиологии стал выход из печати в 1966 г. капитального труда «Термические поражения» [28], удостоенного первой премии министра здравоохранения 
СССР. В ней Т.Я. Арьев аргументированно обосновал несостоятельность целого ряда устаревших к тому времени постулатов и взглядов на ключевые вопросы термической травмы. В частности, подверг мотивированной критике господствовавшее в то время увлечение консервативным местным лечением ожогов и отморожений, ряд существовавших теорий патогенеза и клиники ожоговой болезни, решительно выступил за разработку новых и совершенствование имеющихся способов хирургического лечения ожогов и отморожений.

Занимая высокую административную должность, Т.Я. Арьев не забывал своевременно поздравить коллег, с которыми он начинал свою научно-педагогическую и клиническую работу еще в адъюнктуре в 1930-е гг., с которыми долгое время работал, создавал новую кафедру и достиг выдающихся результатов. Таким человеком был доктор медицинских наук профессор полковник медицинской службы Вениамин Николаевич Шейнис. В канун его юбилея была опубликована статья «Вениамин Николаевич Шейнис (к 60-летию со дня рождения)» [29].

Таким образом, в нашей стране в 1950-х гг. проводились интенсивные научные исследования по проблеме «Ожоги». Были развернуты первые специализированные койки и отделения для лечения обожженных в Ленинграде, Москве, Саратове. Это не было выполнением плановой государственной программы. Данный процесс правильнее назвать реализацией решений выдающихся отечественных хирургов, сумевших предвидеть и оценить значимость, актуальность, а также перспективу исследований по проблеме «Ожоги». Большой вклад внесли ученые и врачи из научно-исследовательских и медицинских учреждений, работавшие во многих регионах и городах нашей страны. Именно благодаря им к началу 1960-х гг. был заложен фундамент теории и практики лечения патогенеза, клиники, диагностики и лечения ожогов. И в этой напряженной и многогранной работе активную роль играл коллектив кафедры термических поражений и ее руководитель - профессор Т.Я. Арьев. А подтверждением тому является представленная читателю в цикле наших работ разнообразная тематика 149 публикаций и научных исследований, которые были созданы и проведены им в период с 1932 по 1975 г. Кроме того, использование полученных результатов в повседневной клинической работе позволило кафедральному коллективу не только существенно улучшить качество оказываемой помощи больным, но и разработать необходимые учебные программы, воспитать школу высококвалифицированных отечественных комбустиологов, поделиться передовыми знаниями с зарубежными коллегами.

\section{СПИСОК ЛИТЕРАТУРЫ}

1. Арьев Т.Я., Повстяной Н.Е. Об оперативном лечении ожогов // Сборник научных трудов Саратовского медицинского института (военно-медицинский факультет). Саратов, 1958. Вып. 3. С. 48-57. 2. Постников Б.Н. Термические ожоги. Л.: Медгиз, 1957. 234 с. 3. Клячкин Л.М., Пинчук В.М. Ожоговая болезнь (Клиника, патогенез, патологическая анатомия и лечение). Л.: Медицина, 1969. 479 c.

4. Колесников И.С., Шейнис В.Н. Основные положения лечения ожогов за рубежом // Вестник хирургии имени Грекова. 1956. T. 77, № 7. С. 111-124.

5. Долинин В.А. Напалмовые ожоги и их лечение на этапах медицинской эвакуации: в 2-х Т.: дис. ... д-ра. мед. наук. Л., 1960. T. 1.420 c., T. 2.428 c.

6. Научная конференция по проблеме ожогов (6-8 мая 1959 г.): тезисы докладов / под ред. Т.Я. Арьева, Е.В. Гублера. Л.: ВМОЛА. 1959. $87 \mathrm{c}$.

7. Колесников И.С., Шейнис В.Н., Вихриев Б.С., Филатов В.И. К обеспечению работы специализированного ожогового отделения для лечения обожженных // Вестник хирургии имени Грекова. 1960. Т. 84, № 4. С. 128-134.

8. Wilson W.C., McGregor A.R., Stewart C.P. Clinical course and pathology of burns and scalds under modern methods of treatment // Brit. J. Surg. 1938;25(100):826-865. DOI: 10.1002/bjs. 18002510012

9. Арьев Т.Я. О влиянии утрат кожного покрова на летальность, патогенез и принципы лечения ожоговой болезни // Хирургия. 1962. № 7. С. 101-106.
10. Колесников И.С., Арьев Т.Я. 0 некоторых спорных вопросах современного лечения ожогов // Вестник хирургии имени Грекова. 1960. Т. 84, № 6. С. 48-53.

11. Арьев Т.Я. 0 влиянии утрат кожного покрова на летальность, принципы лечения и патогенез ожоговой болезни // Ожоговая болезнь: тезисы докладов второй научной конференции по проблеме ожогов, Ленинград, 30 мая - 1 июня 1961 г. / отв. ред. Т.Я. Арьев. Л., 1961. С. 3.

12. Арьев Т.Я. Ожоговая болезнь (клиника, патогенез, принципы лечения) // Клиническая медицина. 1962. Т. 40, № 3. С. 7-19.

13. Арьев Т.Я. Достоверное, вероятное и сомнительное в современных представлениях об ожоговой болезни // Вестник хирургии имени Грекова. 1967. Т. 99, № 7. С. 95-101.

14. Арьев Т.Я., Баткин А.А., Гублер Е.В. и др. Современные представления об ожоговом шоке // Клиническая хирургия. 1968. № 3. С. 1-6.

15. Колесников И.С., Арьев Т.Я. Местное лечение ожогов // Хирургия. 1959. № 7. С. 26-30.

16. Арьев Т.Я. Хирургия ожогов: критический обзор современной зарубежной литературы // Ортопедия, травматология и протезирование. 1962. № 11. С. 76-86.

17. Арьев Т.Я. Хирургия ожогов // Хирургия. 1963. № 12. С. 29-41. 18. Арьев Т.Я. Некоторые итоги и перспективы развития современной хирургии ожогов // Вестник хирургии имени Грекова. 1965. Т. 95, № 7. С. 3-9.

19. Арьев Т.Я., Крылов К.М. Современная кожная пластика // Хирургия. 1967. № 2. С. 3-8. 
20. Арьев Т.Я., Колесников И.С. 0 некоторых спорных вопросах современного лечения ожогов // Труды ВМОЛА. Т. 114. Л., 1960. C. 67-76.

21. Арьев Т.Я. Проблема ожогов в СССР // Хирургия. 1967. № 10. C. 98-103.

22. Арьев Т.Я. Об особенностях ожогов как травмы человека // Ортопедия, травматология и протезирование. 1967. № 7. C. 41-45.

23. Арьев Т.Я. Второй Всемирный конгресс по проблеме ожогов (Эдинбург, сент. 1965 г.) // Вестник хирургии имени Грекова. 1966. Т. 97, № 7. С. 105-106.

24. Арьев Т.Я., Георгиевский А.С., Шейнис В.Н. Организационные и клинические принципы оказания медицинской помощи и лечения обожженных в условиях современной войны // Военно-медицинский журнал. 1961. № 10. С. 21-26.

25. Арьев Т.Я., Георгиевский А.С., Краморев В.А., Собко Н.И. О транспортировке тяжелообоженных на большие расстояния // Военно-медицинский журнал. 1967. № 10. С. 52-55.

26. Частная хирургия: руководство для врачей: в 3 х т. / сост. Т.Я. Арьев [и др.]. Т. 3: Конечности. М.: Медгиз, 1963. 671 с.

27. Арьев Т.Я. Отморожение. Л.: Медгиз, 1963. 36 с.

28. Арьев Т.Я. Термические поражения. М.: Медицина, 1966. $704 \mathrm{c}$.

29. Арьев Т.Я. Вениамин Николаевич Шейнис (к 60-летию со дня рождения) // Вестник хирургии имени Грекова. 1968. Т. 101, № 9. С. 150.

\section{REFERENCES}

1. Ar'ev TYa, Povstyanoi NE. Ob operativnom lechenii ozhogov. Sbornik nauchnykh trudov Saratovskogo meditsinskogo instituta (voenno-meditsinskii fakul'tet). Saratov;1958;3:48-57. (In Russ.).

2. Postnikov BN. Termicheskie ozhogi. Leningrad: Medgiz; 1957. (In Russ.).

3. Klyachkin LM, Pinchuk VM. Ozhogovaya bolezn' (Klinika, patogenez, patologicheskaya anatomiya i lechenie). Leningrad: Meditsina; 1969. (In Russ.).

4. Kolesnikov IS. Sheinis VN. Osnovnye polozheniya lecheniya ozhogov za rubezhom. Vestnik khirurgii imeni Grekova.1956;77(7):111-124. (In Russ.).

5. Dolinin VA. Napalmovye ozhogi $i$ ikh lechenie na etapakh meditsinskoi evakuatsii: [dissertation]. Leningrad; 1960:(1-2). (In Russ.).

6. Ar'ev TYa, Gubler EV, editors. Nauchnaya konferentsiya po probleme ozhogov (1959 May 6-8): tezisy dokladov. Leningrad: VMOLA; 1959. (In Russ.).

7. Kolesnikov IS, Sheinis VN, Vikhriev BS, Filatov VI. K obespecheniyu raboty spetsializirovannogo ozhogovogo otdeleniya dlya lecheniya obozhzhennykh. Vestnik khirurgii imeni Grekova. 1960;84(4):128-134. (In Russ.).

8. Wilson WC, McGregor AR, Stewart CP. Clinical course and pathology of burns and scalds under modern methods of treatment. Brit. J. Surg. 1938;25(100):826-865. D0I: 10.1002/bjs. 18002510012 9. Ar'ev TYa. 0 vliyanii utrat kozhnogo pokrova na letal'nost', patogenez i printsipy lecheniya ozhogovoi bolezni. Khirurgiya. 1962;(7):101-106. (In Russ.).

10. Kolesnikov IS, Ar'ev TYa. 0 nekotorykh spornykh voprosakh sovremennogo lecheniya ozhogov. Vestnik khirurgii imeni Grekova. 1960;84(6):48-53. (In Russ.).

11. Ar'ev TYa. 0 vliyanii utrat kozhnogo pokrova na letal'nost', printsipy lecheniya i patogenez ozhogovoi bolezni. In: Ar'ev TYa, editor. Ozhogovaya bolezn': tezisy dokladov vtoroi nauchnoi konferentsii po probleme ozhogov; Leningrad, 30 May - 1 June 1961. Leningrad; 1961:3. (In Russ.).

12. Ar'ev TYa. Ozhogovaya bolezn' (klinika, patogenez, printsipy lecheniya). Klinicheskaya meditsina. 1962;40(3):7-19. (In Russ.).

13. Ar'ev TYa. Dostovernoe, veroyatnoe i somnitel'noe v sovremennykh predstavleniyakh ob ozhogovoi bolezni. Vestnik khirurgii imeni Grekova. 1967;99(7):95-101. (In Russ.).
14. Ar'ev TYa, Batkin AA, Gubler EV, i dr. Sovremennye predstavleniya ob ozhogovom shoke. Klinicheskaya khirurgiya. 1968;(3):1-6. (In Russ.).

15. Kolesnikov IS, Ar'ev TYa. Mestnoe lechenie ozhogov. Khirurgiya. 1959;(7):26-30. (In Russ.).

16. Ar'ev TYa. Khirurgiya ozhogov: kriticheskii obzor sovremennoi zarubezhnoi literatury. Ortopediya, travmatologiva i protezirovanie. 1962;(11):76-86. (In Russ.).

17. Ar'ev TYa. Khirurgiya ozhogov. Khirurgiya. 1963;(12):29-41. (In Russ.).

18. 18. Ar'ev TYa. Nekotorye itogi i perspektivy razvitiya sovremennoi khirurgii ozhogov. Vestnik khirurgii imeni Grekova. 1965;95(7):3-9. (In Russ.).

19. Ar'ev TYa, Krylov KM. Sovremennaya kozhnaya plastika. Khirurgiya. 1967;(2):3-8. (In Russ.).

20. Ar'ev TYa, Kolesnikov IS. 0 nekotorykh spornykh voprosakh sovremennogo lecheniya ozhogov. In: Trudy VMOLA. Leningrad; 1960; 114:67-76. (In Russ.).

21. Ar'ev TYa. Problema ozhogov v SSSR. Khirurgiya. 1967;(10):98103. (In Russ.).

22. Ar'ev TYa. Ob osobennostyakh ozhogov kak travmy cheloveka. Ortopediya, travmatologiya i protezirovanie. 1967;(7):41-45. (In Russ.). 23. Ar'ev TYa. Vtoroi Vsemirnyi kongress po probleme ozhogov (Edinburgh, sept 1965). Vestnik khirurgii imeni Grekova. 1966;97(7):105-106. (In Russ.).

24. Georgievskii AS, Ar'ev TYa, Sheinis VN. Organizatsionnye i klinicheskie printsipy okazaniya meditsinskoi pomoshchi i lecheniya obozhzhennykh v usloviyakh sovremennoi voiny. Voennomeditsinskii zhurnal. 1961;(10):21-26. (In Russ.).

25. Ar'ev TYa, Georgievskii AS, Kramorev VA, Sobko NI. 0 transportirovke tyazheloobozhennykh na bol'shie rasstoyaniya. Voenno-meditsinskii zhurnal. 1967;(10):52-55. (In Russ.).

26. Ar'ev TYa, et al. Chastnaya khirurgiya: rukovodstvo dlya vrachei: in 3 vol. Vol. 3: Konechnosti. Moscow: Medgiz; 1963. (In Russ.).

27. Ar'ev TYa. Otmorozhenie. Leningrad: Medgiz; 1963. (In Russ.).

28. Ar'ev TYa. Termicheskie porazheniya. Moscow: Meditsina; 1966. (In Russ.).

29. Ar'ev TYa. Veniamin Nikolaevich Sheinis (k 60-letiyu so dnya rozhdeniya). Vestnik khirurgii imeni Grekova. 1968;101(9):150. (In Russ.). 
ОБ АВTOPAX

*Владимир Андреевич Соколов, кандидат медицинских наук; e-mail: vsokolov60@mail.ru; ORCID: 0000-0002-9103-4513

Светлана Анатольевна Мамаева, кандидат педагогических наук; e-mail: svetanma@list.ru; SI SPIN: 4240-8872;

AUTHOR: 507980; ORCID: 0000-0001-6775-1958;

RESEARCHER: X-8369-2018

Ярослав Любомирович Бутрин, помощник начальника клиники; e-mail: butrin_ial@mail.ru; ORCID: 0000-0003-4260-8578; SPIN-код: 8004-0292

Александра Андреевна Герасимова, библиограф; e-mail:vmeda_118@mil.ru
AUTHORS INFO

*Vladimir A. Sokolov, candidate of medical sciences; e-mail:vsokolov60@mail.ru; ORCID: 0000-0002-9103-4513

Svetlana A. Mamaeva, candidate of pedagogical sciences; e-mail: svetanma@list.ru; SI SPIN: 4240-8872; Author: 507980; ORCID: 0000-0001-6775-1958; RESEARCHER: X-8369-2018

Yaroslav L. Butrin, assistant head of the clinic; e-mail: butrin_ial@mail.ru; ORCID: 0000-0003-4260-8578; SPIN-cod: 8004-0292

Alexandra A. Gerasimova, bibliographer; e-mail:vmeda_118@mil.ru 